УДК 624.01

DOI https://doi.org/10.32851/tnv-tech.2021.5.9

\title{
ВДОСКОНАЛЕННЯ МЕТОДИКИ РОЗРАХУНКУ ПРОГИНУ ОДНОСХИЛОЇ БАЛКИ ЗА ЗМІННОЇ ЖОРСТКОСТІ ЗА ДОВЖИНОЮ
}

\author{
Янін О.є. - кандидат технічних наук, \\ доцент кафедри будівництва, архітектури та дизайну \\ Херсонського державного аграрно-економічного університету \\ ORCID ID: 0000-0003-0230-8669 \\ Scopus-Author ID: 57219482395
}

У статті наведено рішення теоретичної задачі визначення прогину односхилої балки за лінійної зміни жсрсткості вздовж прольоту. Актуальність розв'язання такої задачі зумовлена необхідністю забезпечення умов нормальної експлуатації та дотримання вимог техніки безпеки. Вдосконалення методу визначення максимальних прогинів балочних елементів базується на тому, щзо, згідно з нормами проєктування залізобетонної балки, прогин треба обраховувати за загальними правилами будівельної механіки. Розглядається випадок, коли напруження в конструкиії набагато менше за граничні значення. Тоді пластичний складник деформацї порівняно малий.

Об'єктом теоретичного дослідження є однопрольотна шарнірно обперта односхила балка прямокутного поперечного перерізу, яка завантажена рівномірно розподіленим лінійним навантаженням. Більшість сталевих $і$ залізобетонних балок мають двотавровий поперечний переріз, для якого осьовий момент інериії у площчині згину приблизно пропориійний кубу висоти. Тому для спрощення взято прямокутний переріз.

Виходячи з геометричної схеми балки, отримано лінійну залежність між координатою вздовж прольоту та ї̈ висотою. На ичй підставі складена функція осьового моменту інериії поперечного перерізу.

Для отримання аналітичної формули прогинів $і$ кутів повороту балки за довжиною прольоту виконано інтегрування диференційного рівняння зігнутої осі. Згинальний момент у перерізі балки від заданого лінійного навантаження представлений у вигляді квадратичної залежності.

Послідовне інтегрування диференційного рівняння дозволило отримати функиії кута повороту і прогину. Постійні інтегрування виходять з того, щяо прогини на лівій $і$ правій опорах дорівнюють нулю.

Для практичного підтвердження правильності отриманого результату для прогинів розглядався випадок, коли ухил балки дорівнює нулю. Аналіз формули деформаџій балки показав, щуо треба розкривати математичну невизначеність за допомогою правила Лопіталя. Таке завдання пов'язане з певними математичними труднощами і вирішувалося за допомогою комп 'ютерного середовища MathCAD.

Задача знаходження прогинів $і$ кутів повороту балки була розв'язана за контрольних вихідних даних. За допомогою комп ютерного середовища МаthCAD було безпосередньо отримане графічне рішення диференційного рівняння зігнутої осі, а також побудовані графіки функцій прогинів і кутів повороту.

Аналіз циих графіків показав, щзо максимальний прогин і нульовий кут повороту мають одну абсиису, щчо відповідає теоретичним передумовам. Доведено, щио балка має максимальний прогин не посередині прольоту, а ближче до лівої опори, де ї̈ висота менша.

Ключові слова: односхила балка, прогин, кут повороту, змінна жорсткість вздовж прольоту, диференційне рівняння зігнутої осі.

Yanin O.E. Improvement of the technique for calculating the deflection of a single-inclined beam with variable rigidity along length

The article discusses the solution of the theoretical problem of determining the deflection of a single-inclined beam with a linear change in stiffness along the span. The urgency of solving such a problem is due to the need to ensure normal operating conditions and comply with safety conditions. The improvement of the method for determining the maximum deflections of beam elements is based on the fact that, according to the design standards of a reinforced concrete beam, the deflection must be determined according to the general rules of structural mechanics. 
The case is considered when the stress in the structure is much less than the limiting value. Then the plastic component of deformation is relatively small.

The object of theoretical research is a single-span hingedly supported single-inclined beam of rectangular cross-section, loaded with a uniformly distributed linear load. Most steel and reinforced concrete beams have I-beams cross section, for which the axial moment of inertia in the bending plane is roughly proportional to the cube of the height. Therefore, for simplicity, a rectangular section is adopted.

Based on the geometric scheme of the beam, a linear relationship was obtained between the coordinate along the span and its height. On this basis, the function of the axial moment of inertia of the cross section is compiled.

To obtain an analytical formula for the deflections and angles of beam rotation along the length of the span, the differential equation of the curved axis was integrated. The bending moment in the beam section from a given linear load is presented as a quadratic dependence.

Successive integration of the differential equation made it possible to obtain the functions of the angle of rotation and deflection. Integration constants are found on the assumption that the deflections on the left and right supports are equal to zero.

For practical confirmation of the correctness of the result obtained for deflections, a special case was considered when the slope of the beam is equal to zero. Analysis of the deformation formula of the beam showed that it is necessary to disclose the mathematical uncertainty using the Lopital's rule. This problem is associated with certain mathematical difficulties, and it was solved using the MathCAD computer environment.

The problem of finding the deflections and angles of rotation of the beam was solved with the control initial data. Using the computer environment MathCAD, a graphical solution to the differential equation of the curved axis was directly obtained, and graphs of the functions of deflections and angles of rotation were also built.

Analysis of these graphs showed that the maximum deflection and zero angle of rotation have the same abscissa, which corresponds to the theoretical assumptions. It was shown that the beam has a maximum deflection not in the middle of the span, but closer to the left support, where its height is less.

Key words: single-inclined beam, deflection, angle of rotation, variable stiffness along the span, differential equation of a curved axis.

Залізобетонні та металеві балки широко застосовуються у промислових, громадських і житлових будівлях в якості ригелів, а також несучих елементів перекриттів та покриттів. Для забезпечення умов нормальної експлуатації й дотримання вимог техніки безпеки такі конструкції повинні мати певну жорсткість, виходячи $з$ технологічних, конструктивних й естетичних норм. Тому необхідно вдосконалити методи визначення максимальних прогинів балочних елементів. Вони можуть мати різні форми і розміри, яким відповідають певні математичні методи визначення деформацій. Згідно з чинними нормами $[1 ; 2]$ прогин залізобетонної балки треба визначати за загальними правилами будівельної механіки 3 урахуванням пружно-пластичних властивостей матеріалів. Якщо напруження у конструкції набагато менше за граничні значення, то пластичний складник деформації порівняно малий. У такому разі відбуваються переважно пружні

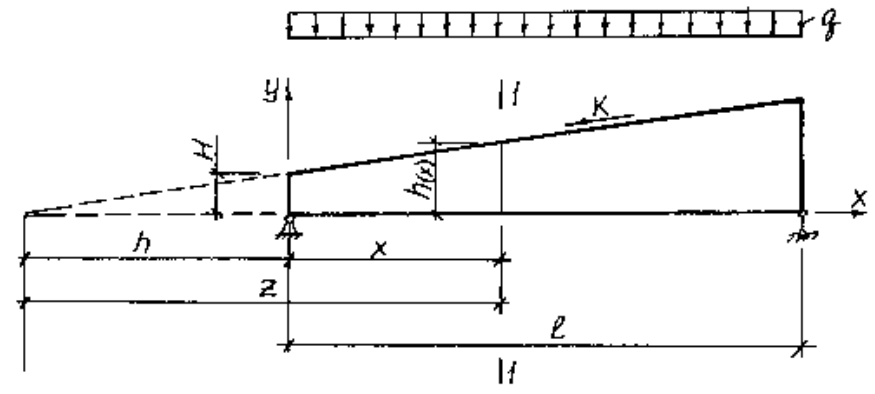

Рис. 1. Розрахункова схема балки 
деформації. Згідно з нормативними вимогами [3] визначений максимальний прогин балки не повинен перевищувати граничне значення.

Розглянемо однопрольотну шарнірно обперту односхилу балку прямокутного поперечного перерізу, яка завантажена рівномірно розподіленим лінійним навантаженням $q$ [4] (рис. 1). Припустимо, що матеріал працює пружно.

Більшість сталевих і залізобетонних балок мають двотавровий поперечний переріз, для якого осьовий момент інерції у площині згину приблизно пропорційний кубу висоти [5-6]. Тому для спрощення можна розглядати прямокутний переріз.

Відстань від лівої опори до точки перетину ліній верху і низу балки позначимо h. Тоді:

де $\boldsymbol{H}$ - висота балки на лівій опорі; $h=\frac{H}{k}$,

$\boldsymbol{\kappa}-$ ухил верхнього поясу балки.

Положення поперечного перерізу балки за довжиною будемо характеризувати абсцисою $\boldsymbol{x}$ або $\boldsymbol{z}=\boldsymbol{h}+\boldsymbol{x}$. Змінна висота балки на відстані $\boldsymbol{x}$ від лівої опори з урахуванням формули (1):

$$
h_{(x)}=H+k x=k(h+x) .
$$

Тоді осьовий момент інерції поперечного перерізу в цьому місці:

$$
I_{(x)}=\frac{b h_{(x)}^{3}}{12}=\frac{b k^{3}(h+x)^{3}}{12},
$$

де $\boldsymbol{b}$ - ширина поперечного перерізу балки.

Щоб отримати аналітичну формулу прогинів і кутів повороту балки за довжиною прольоту, треба проінтегрувати диференційне рівняння зігнутої осі, яке має вигляд:

$$
y^{\prime \prime}=\frac{M_{(x)}}{E \cdot I_{(x)}},
$$

де $\boldsymbol{M}_{(x)}$ - згинальний момент у перерізі балки від заданого лінійного навантаження q:

$$
M_{(x)}=\frac{1}{2} q x(l-x)
$$

де $\boldsymbol{l}$ - проліт балки.

Після підстановки у диференційне рівняння (4) виразів для $I_{(x)}$ i $M_{(x)}$ ф формул (3) та (5) отримуємо:

$$
y^{\prime \prime}=\frac{6 q}{E b k^{3}} \frac{x(l-x)}{(h+x)^{3}}=\frac{6 q}{E b k^{3}} \frac{(z-h)(l-z+h)}{z^{3}} .
$$

Послідовно інтегруючи його, одержимо функції кута повороту і прогину:

$$
\begin{gathered}
y^{\prime}=\varphi=\frac{6 q}{E b k^{3}}\left[-\ln z-\frac{l+2 h}{z}+\frac{h(l+h)}{2 z^{2}}+c\right] ; \\
y=\frac{6 q}{E b k^{3}}\left[-(z+l+2 h) \ln z+z(c+1)-\frac{h(l+h)}{2 z}+d\right] .
\end{gathered}
$$

Постійні інтегрування $\boldsymbol{c}$ i $\boldsymbol{d}$ знайдемо, виходячи 3 того, що прогини на лівій і правій опорах дорівнюють нулю:
1) за $\boldsymbol{x}=0$ (або $\boldsymbol{z}=\boldsymbol{h}) \boldsymbol{y}=0$;
2) за $\boldsymbol{x}=1($ або $\boldsymbol{z}=\boldsymbol{h}+\boldsymbol{l}) \boldsymbol{y}=0$. 
66

У результаті отримуємо систему рівнянь:

$$
\begin{gathered}
-(h+l+2 h) \ln h+h(c+1)-\frac{(l+h)}{2}+d=0 ; \\
-(h+l+l+2 h) \ln (h+l)+(h+l)(c+1)-\frac{h}{2}+d=0 .
\end{gathered}
$$

Звідки

$$
\begin{gathered}
c=\left(2+\frac{3 h}{l}\right) \ln (h+l)-\left(1+\frac{3 h}{l}\right) \ln h-\frac{3}{2} ; \\
d=\left(4 h+l+\frac{3 h^{2}}{l}\right) \ln h-\left(2 h+\frac{3 h^{2}}{l}\right) \ln (h+l)+\frac{l}{2}+h .
\end{gathered}
$$

Після підстановки знайдених постійних інтегрування $\boldsymbol{c}$ та $\boldsymbol{d}$ у формули (7) і (8) будемо мати за $\boldsymbol{z}=\boldsymbol{h}+\boldsymbol{x}$ :

$$
\begin{gathered}
y=\frac{6 q h^{3}}{E b H^{3}}\left[(x+l+3 h) \ln \frac{h}{h+x}+\left(2 x+\frac{3 h(h+x)}{l}-\right.\right. \\
\left.\left.-\frac{3 h^{2}}{l}\right) \ln \frac{h+l}{h}+\frac{h}{2}-\frac{x}{2}+\frac{l}{2}-\frac{h(l+h)}{2(h+x)}\right] ; \\
y^{\prime}=\varphi=\frac{6 q h^{3}}{E b H^{3}}\left[\ln \frac{h}{h+x}+\left(2+\frac{3 h}{l}\right) \ln \frac{h+l}{h}-\right. \\
\left.-\frac{10 h x+h l+2 x l+3 x^{2}+6 h^{2}}{2(h+x)^{2}}\right] .
\end{gathered}
$$

Щоб підтвердити правильність отриманої формули для прогинів, доцільно розглянути частковий випадок, коли ухил балки $\boldsymbol{\kappa}=0$ i $\boldsymbol{h} \rightarrow \infty$. Для цього треба знайти $\lim _{h \rightarrow \infty} y$. Аналізуючи формулу (13), можна дійти висновку, що існує потреба розкривати невизначеність, наприклад, за допомогою правила Лопіталя [7]. Така задача пов'язана з певними математичними труднощами, тож їі доцільно вирішувати за допомогою комп'ютерного середовища МathCAD. B результаті було отримано, що:

$$
\lim _{h \rightarrow \infty} y=-\frac{1}{2} q x \frac{\left(-2 x^{2} l+x^{3}+l^{3}\right)}{E b H^{3}} .
$$

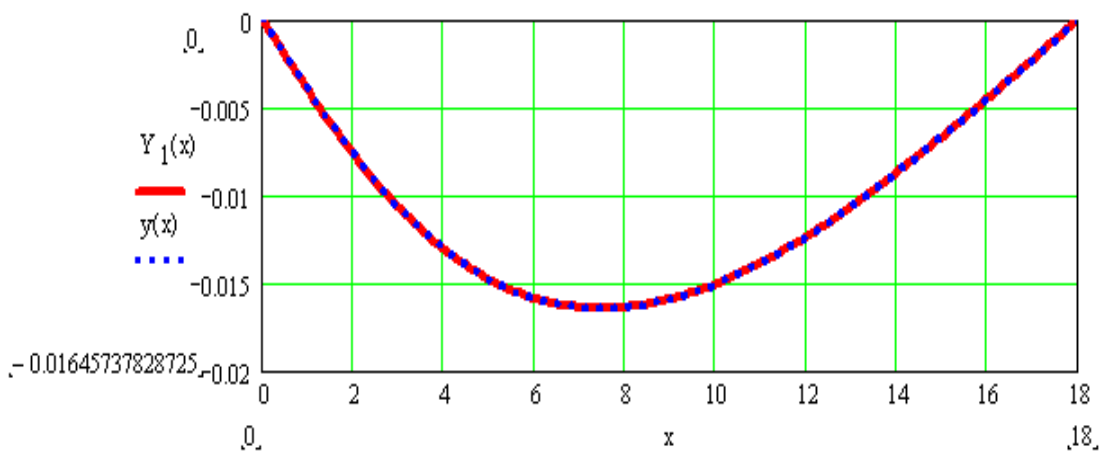

Рис. 2. Графік прогинів балки 


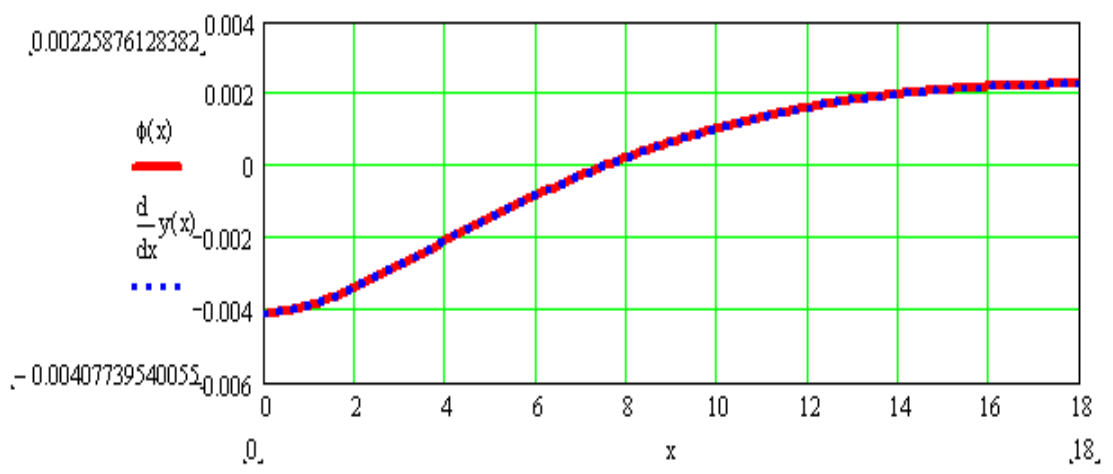

Рис. 3. Графік кутів повороту балки

Цей вираз збігається з відомою формулою [8]. Таким чином, формула для прогину (13) отримала певне підтвердження.

Задача знаходження прогинів і кутів повороту балки була розв'язана за таких контрольних вихідних даних: $\boldsymbol{l}=18 \mathrm{м} ; \boldsymbol{H}=0,9$ м; $\boldsymbol{k}=1 / 12 ; \boldsymbol{q}=30$ кН/м; $\boldsymbol{E}=30000 \mathrm{MПа} ; \boldsymbol{b}=0,3 \mathrm{H}$.

За допомогою комп'ютерного середовища MathCAD було безпосередньо отримане графічне рішення диференційного рівняння зігнутої осі (6), яке було позначене $\mathrm{Y}_{1}(\mathrm{x})$, а також побудовані графіки функцій, згідно з формулами (13) і (14). Вони наведені на рис. 2 і 3.

На рис. 2 графіки $\mathrm{y}(\mathrm{x})$ i $\mathrm{Y}_{1}(\mathrm{x})$ співпали, що $є$ ще одним підтвердженням правильності виконаних математичних перетворень. Таке підтвердження є дуже важливим з погляду адекватності запропонованого результату.

Із графіків видно, що максимальний прогин і нульовий кут повороту мають одну абсцису $\mathrm{x}=7,5 \mathrm{~m}<1 / 2=9$ м. Тобто балка має максимальний прогин не посередині прольоту, а ближче до лівої опори, де її висота менша.

\section{СПИСОК ВИКОРИСТАНОЇ ЛІТЕРАТУРИ:}

1. ДБН В.2.6-98:2009. Бетонні та залізобетонні конструкції. Основні положення / Міністерство регіонального розвитку та будівництва України. Київ, 2011. 71 с.

2. ДСТУ Б В.2.6-156:2010. Бетонні та залізобетонні конструкції з важкого бетону. Правила проєктування / Міністерство регіонального розвитку та будівництва України. Київ, 2011. 118 с.

3. ДСТУ Б В.1.2-3 2006. Прогини і переміщення. Вимоги проєктування / Міністерство регіонального розвитку та будівництва України. Київ, 2006. 10 с.

4. ДБН В.1.2-2:2006. Навантаження і впливи. Норми проєктування / Міністерство регіонального розвитку та будівництва України. Київ, 2006. 78 с.

5. Вахненко П.Ф. Залізобетонні конструкції. Київ : Урожай, 1995. 368 с.

6. Мандриков А.П. Примеры расчета железобетонных конструкций : учебное пособие для техникумов. 2-е изд., перераб. и доп. Москва : Стройиздат, 1989. 506 с.

7. Пискунов Н.С. Дифференциальное и интегральное исчисления для втузов. Москва : Физматгиз, 1963. 856 с.

8. Сопротивление материалов : учебник для вузов / под ред. А.Ф. Смирнова. Изд. 3-е, перераб. и доп. Москва : Высшая школа, 1975. 480 с. 


\section{REFERENCES:}

1. DBN V.2.6-98:2009 (2011) Betonni ta zalizobetonni konstruktsiyi. Osnovni polozhennya / Ministerstvo rehional'noho rozvytku ta budivnytstva Ukrayiny. Kyyiv. $71 \mathrm{~s}$. [in Ukrainian]

2. DSTU B V.2.6-156:2010 (2011) Betonni ta zalizobetonni konstruktsiyi z vazhkoho betonu. Pravyla proektuvannya / Ministerstvo rehional'noho rozvytku ta budivnytstva Ukrayiny. Kyyiv. 118 s. [in Ukrainian]

3. DSTU B V.1.2-3 2006 (2006) Prohyny ta peremishchennya. Vymohy proektuvannya / Ministerstvo rehional'noho rozvytku ta budivnytstva Ukrayiny. Kyyiv. 10 s. [in Ukrainian]

4. DBN V.1.2-2:2006 (2006) Navantazhennya ta vplyvy. Normy proektuvannya / Ministerstvo rehional'noho rozvytku ta budivnytstva Ukrayiny. Kyyiv. 78 s. [in Ukrainian]

5. Vakhnenko, P.F. (1995) Zalizobetonni konstruktsiyi. Kyyiv : Urozhay. 368 s. [in Ukrainian]

6. Mandrykov, A.P. (1989) Prymery rascheta zhelezobetonnykh konstruktsyy : uchebnoe posobye dlya tekhnykumov. 2-e yzd., pererab. y dop. M. : Stroyyzdat. $506 \mathrm{~s}$. [in Russian]

7. Pyskunov, N.S. (1963) Dyfferentsyal'noe y yntehral'noe yschyslenyya dlya vtuzov. M. : Fyzmathyz. 856 s. [in Russian]

8. Soprotyvlenye materyalov : uchebnyk dlya vuzov (1975) / pod red. A.F. Smyrnova. Yzd. 3-e, pererab. y dop. M. : Vysshaya shkola. 480 s. [in Russian] 